\title{
Anistiados da Vale e Identificação Organizacional
}

\section{Amnestied of Vale and Organizational Identification}

\author{
Ana Carla Coelho Assis' (orcid.org/0000-0002-5895-5067) \\ Adriana Ventola Marra ${ }^{2}$ (orcid.org/0000-0003-3405-0308) \\ Samara de Menezes Lara ${ }^{3}$ (orcid.org/0000-0001-6039-3684)
}

\begin{abstract}
Resumo
Este artigo tem por objetivo compreender o processo de identificação das pessoas irregularmente demitidas da Companhia Vale do Rio Doce (CVRD) durante o governo Collor e reintegradas ao serviço público a partir de 2011, em relação à Universidade Federal de Itajubá (Unifei). Esses trabalhadores são chamados de “anistiados” pela Lei n. 8.878/94. Entende-se que o processo de identificação com a organização na qual o anistiado foi reintegrado assume um papel fundamental na construção de sua identidade. Num estudo qualitativo-descritivo, foram realizadas 21 entrevistas semiestruturadas, representação gráfica e levantamento da avaliação de desempenho, sendo que a análise dos dados foi por análise de conteúdo. Como resultados destacam-se sentimentos de gratidão em relação à Universidade, alto grau de identificação com a Universidade e com a Vale e atuação pouco efetiva na Universidade. As expectativas acerca do desempenho dos anistiados são baixas e não existe nenhum processo de gestão de seu desempenho.
\end{abstract}

Palavras-chave: Anistia. Identificação organizacional. Desempenho individual.

\begin{abstract}
This paper aims to understand the process of identifying the people irregularly dismissed from Vale do Rio Doce Company (CVRD) during the Collor government and reintegrated into the public service as of 2011, in relation to the Federal University of Itajubá (Unifei). These workers are called “amnestied” by Law 8.878/94. It is understood that the identification process with the organization in which the amnestied was reinstated assumes a fundamental role in the construction of their identity. In a qualitative-descriptive study, 21 semi-structured interviews, graphical representation and performance evaluation were conducted, and data analysis was by content analysis. As a result, stand out feelings of gratitude in relation to the University, a high degree of identification with the University and with Vale and ineffective performance at the University. Expectations about the performance of the amnestied are low and there is no process of managing their performance.
\end{abstract}

\footnotetext{
${ }^{1}$ Universidade Federal de Viçosa, Viçosa, Brasil. E-mail: anacarlassis@gmail.com.

2 Universidade Federal de Viçosa, Viçosa, Brasil. E-mail: aventola@ufv.br

${ }^{3}$ Universidade Federal de Minas Gerais, Belo Horizonte, Brasil. E-mail: mgsamaralara@gmail.com.
} 
Keywords: Amnesty. Organizational identification. Individual performance. 


\section{Introdução}

No período de março de 1990 a outubro de 1992, durante o governo de Collor de Mello, foram realizadas a privatização de empresas públicas, a extinção de órgãos e a demissão e disponibilidade de funcionários públicos federais. Foram demitidos aproximadamente 150 mil pessoas, de várias organizações, entre elas a Companhia Vale do Rio Doce - CVRD (Azevedo, 2016). Esses funcionários precisaram retornar ao mercado de trabalho em um contexto de recessão econômica, inflação e altos índices de desemprego (Brasil, 2015). Em Itabira/MG, cidade cuja principal atividade econômica era a mineração realizada pela CVRD, foram demitidos cerca de 300 funcionários da CVRD nesse período (Andrade, 2013).

Com as denúncias de irregularidades no governo Collor, as demissões começaram a ser questionadas. Assim, em 23 de junho de 1993, Itamar Franco decretou a criação de uma Comissão Especial para analisar as referidas demissões (Decreto n. 93, 1993). O trabalho da comissão resultou na promulgação da Lei $n^{\circ}$ 8.878, de 11 de maio de 1994, que concedeu o direito de anistia às pessoas irregularmente demitidas (Azevedo, 2016).

O tempo médio decorrido entre a demissão e a reintegração dos antigos funcionários da CVRD foi de 20 anos, sendo eles incorporados ao quadro do Departamento Nacional de Produção Mineral (DNPM), ao qual a CVRD era vinculada antes da privatização mas como o DNPM não comportaria todos os funcionários reintegrados, muitos foram cedidos a outras instituições. Uma dessas instituições foi a Universidade Federal de Itajubá (Unifei) Campus de Itabira. Os primeiros anistiados foram recebidos pela Unifei em 2011 e, em julho de 2016, existiam 80 funcionários anistiados lotados no Campus. No mesmo período, o Campus de Itabira contava com 77 Servidores Técnico-Administrativos em Educação (STAEs).

Embora sejam, em número, maioria na Unifei, os anistiados, em geral, ocupam cargos de baixa complexidade, têm participação restrita nos processos de decisão e não têm alguns direitos, como a realização de cursos externos de capacitação, financiados pela Unifei. Muitos têm idade avançada e dificuldade em executar as atividades previstas para o cargo.

Diante do exposto, o principal objetivo deste estudo foi compreender o processo de identificação e suas implicações para o desempenho no trabalho dos funcionários anistiados cedidos à Unifei. Como objetivos específicos, buscou-se conhecer o processo de anistia da CVRD, compreendendo os significados que este representou para as pessoas envolvidas; verificar a intensidade da identificação dos entrevistados com a Unifei e analisar as implicações da identificação dos anistiados entrevistados com a Universidade e o desempenho destes no trabalho. Tem-se como pressuposto, a partir da teoria da identidade social (Ashforth \& Mael, 1989; Ashforth, Harrison \& Corley, 2008), que o processo de identificação com a organização na qual o 
anistiado trabalha assume um papel fundamental na construção de sua identidade.

A identificação organizacional constitui o processo a partir do qual a pessoa integra a identidade organizacional na sua autopercepção (Fernandes, Marques \& Carrieri, 2009), ou seja, diz respeito ao que a pessoa é em relação à organização, ocorrendo quando as opiniões do indivíduo sobre a organização são utilizadas para definir a si próprio (Pratt, 1998).

Como o processo de reintegração dos anistiados ainda é recente e existem poucos estudos sobre esse assunto, a realização da pesquisa proposta mostrou-se relevante também para outras organizações que receberam esses funcionários. Especificamente sobre a reintegração dos anistiados nas organizações, Azevedo (2016) relata o histórico das lutas dos anistiados na Universidade Federal Rural do Rio de Janeiro; e Prata (2013) aborda o prazer e o sofrimento vivenciados pelos reintegrados no Cefet-MG. Contudo, não foram encontrados estudos que abordem os processos de identificação organizacional e sua relação com o desempenho dos anistiados.

\section{Referencial Teórico}

\section{Processos de Identificação}

Os processos de identificação têm como foco o relacionamento do indivíduo com outras pessoas e grupos sociais. Trata-se dos processos nos quais os indivíduos se definem, comunicam para os outros essa identificação e a utilizam em sua vida cotidiana (Ashforth et al., 2008) e decorrem da necessidade do ser humano de fazer parte de algum grupo, em que, geralmente, os membros têm perfil semelhante (Mourão et al., 2014).

Para Ashforth e Mael (1989), esse agrupamento psicológico, no qual algumas pessoas identificam-se umas com as outras como pertencentes à mesma categoria social e ao mesmo grupo, inicia quando o indivíduo se compara aos demais e percebe-se como único. O indivíduo passa a avaliar os grupos sociais existentes e as características de si mesmo e dos outros, de modo a se perceber como membro de determinados grupos.

Tajfel (1982) apresenta dois componentes necessários para a identificação: o componente cognitivo, que diz respeito ao senso de pertencimento ao grupo, e o componente valorativo, relativo ao valor que representa o pertencimento ao grupo. Um terceiro componente apresentado, ligado aos dois primeiros, diz respeito ao investimento emocional relativo ao pertencimento e à valorização. Assim, o indivíduo sente a necessidade de fazer parte de um grupo para melhorar a autoestima (Ashforth, et al., 2008), buscar segurança e reduzir a incerteza (Pratt, 1998).

Para Pratt (1998), o processo de identificação está relacionado a quatro necessidades individuais: proteção, afiliação, autovalorização e necessidades holísticas. A necessidade de proteção ocorre quando o indivíduo se sente coagido para fazer parte ou continuar como membro da organização. A afiliação relaciona-se à necessidade do indivíduo de evitar o sentimento de solidão, a partir do pertencimento a um grupo. Para se 
autovalorizar, a pessoa imita o comportamento de outras, que têm características consideradas positivas. As necessidades holísticas seriam a busca das pessoas por valores que lhe proporcionem uma razão para viver, a partir do pertencimento a um grupo.

Um tipo específico de identificação social é a identificação organizacional (Ashforth \& Mael, 1989). Dutton et al. (1994) definem a identificação organizacional como uma forma de ligação psicológica, na qual as características de uma organização são utilizadas por seus membros para definir a si próprios. Isso significa que, no processo de identificação organizacional, os indivíduos passam a reconhecer a identidade da organização em sua própria identidade. Quando os indivíduos se definem em termos de sua filiação organizacional, eles percebem uma sobreposição entre seus atributos e congruência entre seus valores, e a missão organizacional, ideologia, valores, estratégias e formas costumeiras de fazer as coisas (Ashforth \& Mael, 1989).

Dutton et al. (1994) ainda citam outros fatores que podem influenciar o grau de identificação organizacional, como a intensidade e duração do contato entre a organização e seus membros e a imagem organizacional. Para Rho, Yun \& Lee (2015), a imagem organizacional consiste na percepção que as pessoas (internas e externas) têm sobre a organização. Assim, segundo os autores, quando a imagem externa da organização é positiva, a identificação organizacional pode conferir características também positivas para seus membros, de modo que estes se sentem orgulhosos de fazer parte daquele grupo.
Kreiner e Ashforth (2004) esclarecem que a identificação é apenas uma forma de relacionamento entre a organização e seus membros. Nesse sentido, os autores desenvolveram um modelo expandido de análise, que inclui quatro formas nas quais as pessoas podem se definir, considerando as características organizacionais: superidentificação, desidentificação, identificação ambivalente e identificação neutra. Considera-se uma pessoa como superidentificada quando suas principais características foram incorporadas à organização, além da sua identidade como membro da organização ser mais forte do que suas outras identidades (Dutton et al., 1994).

Segundo Kreiner e Ashforth (2004), enquanto a superidentificação está relacionada ao vínculo entre a pessoa e as características organizacionais (geralmente positivo), a desidentificação envolve a desconexão (normalmente negativa) entre o indivíduo e a organização. Assim, no caso da desidentificação, o trabalhador conscientemente se diferencia dos atributos organizacionais, pelos quais nutre um sentimento de repulsa, que pode se aplicar à organização como um todo ou a aspectos específicos.

A identificação ambivalente refere-se à situação na qual um indivíduo simultaneamente se sente identificado e desidentificado com determinados aspectos da organização (Kreiner \& Ashforth, 2004). Os autores ressaltam que, como as organizações são multifacetadas, essa ambivalência não está necessariamente relacionada a aspectos diferentes da organização, mas pode dizer respeito às mesmas 
características. Por fim, a identificação neutra significa que o indivíduo não se sente identificado ou desidentificado com a organização, seja para evitar opiniões extremas, para desvincular sua subjetividade da organização, por estilo de trabalho, seja por outros motivos (Kreiner \& Ashforth, 2004).

Os termos identificação organizacional e comprometimento organizacional muitas vezes se confundem, mas, de acordo com autores como Ashforth et al. (2008), Ashforth e Mael (1989) e Pratt (1998), é preciso estabelecer as diferenças entre eles. Para Ashforth e Mael (1989), o comprometimento está relacionado à crença nos valores e objetivos organizacionais e ao esforço para fazer parte da organização e se manter como membro; a identificação, porém, está mais relacionada a variáveis como atratividade e destino compartilhado com a organização - ou seja, o indivíduo sente-se parte da organização e não pode deixá-la sem perdas psíquicas. Ashforth e Mael (1989) ainda ressaltam que, enquanto a identificação organizacional diz respeito a uma organização específica, o comprometimento pode estar relacionado a várias organizações simultaneamente.

\section{Identificação Organizacional e Desempenho Individual}

Gestores reconhecem a importância dos vínculos que os trabalhadores desenvolvem com o trabalho e com a organização como forma de entender o comportamento dessas pessoas e influenciá-las para o benefício organizacional (Bastos, Rodrigues, Moscon, Silva \& Pinho,
2013). Para Kramer e Faria (2007, p. 86), “о vínculo é uma relação particular com o objeto que resulta numa pauta de conduta, que se traduz na forma observável do vínculo, sendo possível identificar nela (na conduta) a sua expressão (vínculo)". Considerando que esse objeto refere-se à organização, percebe-se que o comportamento do indivíduo em relação à organização expressa o vínculo existente entre ambos. A identificação organizacional é um desses vínculos que pode alavancar, em contrapartida, contribuições dos empregados, como desempenho, comparecimento ao trabalho, permanência na empresa, entre outros (Siqueira \& Gomide Júnior, 2004).

Para Kramer e Faria (2007) e Siqueira e Gomide Júnior (2004), a identificação e o sentimento de pertença/ligação afetiva em relação à organização estão intimamente relacionados, visto que os processos de identificação envolvem o sentimento de fazer parte de um grupo. Assim, quanto mais as pessoas se identificarem com a sua organização de trabalho, maior a probabilidade de elas desempenharem melhor suas funções (Ashforth \& Mael, 1989; Dutton, Dukerich \& Harquail,1994).

Para Ashforth et al., (2008) e Pratt (1998) a identificação organizacional pode reduzir atritos e conflito; promover, em meio aos membros, a adoção de comportamentos condizentes com a organização; aperfeiçoar o cumprimento das obrigações; aumentar o controle da organização sobre seus membros; elevar a satisfação e a motivação e aprimorar a tomada de decisão, que tenderá a ocorrer de acordo com os objetivos organizacionais. Entre 
as consequências para a organização, destacamse a melhora da satisfação no trabalho e no desempenho.

De acordo com Bendassolli e Malvezzi (2013), desempenho é um agrupamento de comportamentos e ações realizados com um propósito definido, que dependem da compreensão do que é esperado naquele contexto. Bendassolli (2012) complementa que o desempenho pode ser avaliado em relação ao nível de proficiência das ações realizadas pelos membros da organização ou o quanto essas ações contribuem para o alcance dos objetivos organizacionais. O desempenho é, então, um insumo para que os objetivos da organização sejam alcançados, uma vez que a ação das pessoas colabora para que a organização apresente resultados, alcance seus objetivos e gere valor (Bendassolli \& Malvezzi, 2013). Como os resultados obtidos promovem O sucesso (ou fracasso) das organizações, o desempenho é um aspecto muito importante para qualquer uma delas (Fogaça \& Coelho Júnior, 2015). Em pesquisa recente, Tavares, van Knippenberg e van Dick (2016) verificaram que o desempenho no trabalho pode variar em função do nível de identificação organizacional do indivíduo. Contudo, os autores ressaltam que a própria equipe e o trabalho em si são geralmente mais influentes como foco de identificação do que a organização como um todo, podendo afetar mais o desempenho individual.

A partir do exposto, ressalta-se a importância de estudar a ocorrência da identificação organizacional e de se analisar os efeitos que esta pode apresentar no desempenho dos trabalhadores. Assim, o presente trabalho busca realizar tal análise em relação a uma categoria específica de trabalhadores da Universidade Federal de Itajubá, Campus de Itabira. Para analisar o nível de identificação desses indivíduos, foram considerados alguns aspectos estabelecidos por Dutton et al. (1994) e Kramer e Faria (2007), e utilizado o modelo expandido de análise criado por Kreiner e Ashforth (2004).

\section{Método}

Este estudo se caracteriza como uma pesquisa qualitativa do tipo descritiva. Assim, buscou-se compreender o ambiente em que os sujeitos vivem e trabalham, atribuindo, a partir dos processos de interação vivenciados, uma multiplicidade de significados subjetivos a esse ambiente (Creswell, 2010).

\section{Participantes}

O universo da pesquisa foi composto pelos anistiados cedidos à Unifei (Campus de Itabira), bem como de gestores e servidores. A partir dos dados da Diretoria de Pessoal, foram selecionados 16 anistiados com diferentes perfis (idade, sexo, escolaridade) e que atuam em diferentes setores. A partir dessa estratificação, a escolha se deu por acessibilidade. Também foram entrevistados cinco servidores que estiveram envolvidos na contratação, alocação e socialização dos anistiados, selecionados por acessibilidade.

No que se refere ao perfil dos anistiados participantes, $81 \%$ são do sexo masculino, 60\% 
estão na faixa etária de 60 a 69 anos e já aposentados pelo INSS. O tempo de Unifei varia de dois a três anos e o nível dos cargos ocupados é operacional.

Por sua vez, $60 \%$ dos servidores entrevistados têm entre 20 e 29 anos e 30 e 39 anos, havendo equilibrados quanto ao sexo. O tempo médio de Unifei é de seis anos e os cargos ocupados são administrativos e de gestão.

\section{Instrumentos de Coleta de Dados}

A coleta de dados ocorreu por meio de entrevistas semiestruturadas, representação gráfica e formulário de avaliação de desempenho (AVD). Destaca-se que os participantes assinaram o Termo de Consentimento Livre e Esclarecido (TCLE) e que se observou o prescrito pelo Comitê de Ética em Pesquisa Envolvendo Seres Humanos, sendo o projeto registrado na Plataforma Brasil - CAAE n. 50967915.4.0000.5153.

$\mathrm{O}$ roteiro de entrevistas abordava $\mathrm{O}$ processo de anistia, a identificação com a universidade, os sentimentos sobre o trabalho e a Instituição, os relacionamentos interpessoais e o reconhecimento pelo trabalho, e a percepção de seu desempenho no trabalho. Os servidores foram questionados sobre o processo de admissão e integração dos anistiados, bem como do desempenho destes no trabalho.

A representação gráfica consistiu em uma adaptação do modelo expandido de identificação proposto por Kreiner e Ashforth (2004). Depois da realização das perguntas abertas, as pesquisadoras apresentaram $\mathrm{O}$ desenho do modelo, descreveram que um círculo representa o entrevistado e o outro, a Unifei, e solicitaram que os funcionários indicassem o quadrante (a, b, c ou d) cujo desenho representava melhor o relacionamento e o sentimento deles em relação à Unifei Campus de Itabira. Entretanto, os quadrantes não foram identificados conforme as situações descritas por Kreiner e Ashforth (2004) superidentificação, identificação neutra, desidentificação e identificação ambivalente para não influenciar as respostas dos entrevistados.

O formulário de avaliação de desempenho utilizado foi adaptado do adotado na Unifei para avaliar os Servidores TécnicoAdministrativos em Educação (STAEs). Optouse por solicitar às chefias que preenchessem um formulário de avaliação para todos os anistiados, sendo que apenas as avaliações relativas aos entrevistados foram analisadas. As entrevistas foram numeradas e codificadas e os anistiados receberam códigos de A1 a A16 e os servidores de S1 a S5.

\section{Coleta e Análise de Dados}

As entrevistas foram agendadas com os participantes e realizadas individualmente, no campus de Itabira. $O$ roteiro de entrevista elaborado constituiu apenas de um guia para a pesquisa, permitindo que os entrevistados expressassem livremente sua subjetividade e que as pesquisadoras observassem melhor as pessoas em seu ambiente (Creswell, 2010). Todas as entrevistas, com duração média de 60 minutos, foram gravadas e transcritas. 
Os dados foram analisados de acordo com a análise de conteúdo de Bardin (1977). Nesse sentido, as respostas dos entrevistados foram categorizadas de acordo com temas recorrentes, que permitiam analisar mais profundamente as mensagens. Os trechos das falas dos entrevistados foram agrupados a partir das categorias intermediárias, que foram agrupadas em terminais, quais sejam: anistia e reintegração, processos de identificação e implicações no desempenho.

\section{Resultados e Discussão}

\section{Anistia e Reintegração}

A demissão na CVRD assumiu diferentes significados para os trabalhadores envolvidos. Esses significados e o impacto dessa demissão variaram de acordo com a relação que tinham com a empresa, com a vida pessoal, bem como com a capacidade de cada um em se reestruturar. As demissões surpreenderam os trabalhadores, que julgavam ter um emprego estável; com isso, todos expressaram, direta ou indiretamente, que se sentiram surpresos e injustiçados com as demissões. O sentimento de injustiça também foi apontado pelos anistiados dos estudos de Azevedo (2016) e Prata (2013). Como disse o entrevistado A6: "na época dessas demissões... Foram muito injustas. Foram bem arbitrárias... Sem nenhum critério. Foi um constrangimento total. Pra todos. Inclusive pra mim, porque... Eu amava aquilo que eu fazia naquela empresa. Tinha uma ficha invejável naquela Vale".
Destaca-se a forte identificação com a CVRD e com o trabalho que exerciam. Assim, considerando a importância que as organizações podem representar para a autodefinição e autoestima dos trabalhadores, quando identificados com as características e valores organizacionais (Fernandes et al., 2009), a demissão arbitrária resultou em mais do que a perda da remuneração, mas também em uma ruptura na identidade profissional. O sentimento de injustiça foi somado ao "constrangimento" perante seus pares e conhecidos e à "perda do chão" (A16). Esse achado corrobora com os resultados da pesquisa de Azevedo (2016), no qual os anistiados estudados não se sentem pertencentes à nova instituição pelo fato de não terem se desvinculado das identidades do cargo que exerciam antes da demissão.

A partir dos depoimentos, ressalta-se a importância que o vínculo de trabalho com a CVRD tinha para a identidade desses trabalhadores. O entrevistado A1 destaca que em Itabira "só tinha valor quem era funcionário da Vale". Assim, ao serem demitidos, passaram a não ter mais valor, ou seja, passam a ser "O resto". Considerando que a identidade é formada também a partir da opinião de outros indivíduos (Dubar, 2005), a mudança no status afeta a percepção dessas pessoas sobre si próprias, bem como de suas relações sociais. Tal fato pode ser percebido neste trecho de A1: “O salário praticamente caiu pela metade. [...] E você ainda tinha todos esses benefícios. [...] Quem não era funcionário da Vale, era marginalizado. Era o resto. Só tinha valor na cidade quem era funcionário da Vale”. 
Foi possível perceber, nos depoimentos dos anistiados, os três componentes da identificação de Tajfel (1982): o cognitivo, o valorativo e o emocional. Os trabalhadores demitidos foram afastados do grupo do qual se sentiam parte, perdendo o valor que tal filiação representava e, consequentemente, sofreram os impactos emocionais decorrentes da quebra dessa ligação. Além da situação descrita, somamse os impactos financeiros da ruptura, que afetaram não apenas o padrão de vida dos trabalhadores e de seus familiares, mas também sua autoestima.

A partir do sentimento de injustiça pela demissão e de todas as consequências desta para os antigos funcionários, iniciou-se um movimento em busca do retorno à CVRD. Esse movimento começou logo depois das demissões, ainda em 1992. Desde esse período, algumas pessoas e instituições assumiram a liderança do processo e buscaram cadastrar as pessoas demitidas, agendar reuniões e procurar apoio político, em prol da reintegração dos demitidos. Entretanto, o movimento parece ter se tornado mais forte a partir da promulgação da Lei n. 8.878/1994, art. $1^{\circ}$, que determinou a anistia aos servidores públicos que tinham sido exonerados ou demitidos.

O retorno dos anistiados ocorreu no mesmo regime jurídico que tinham na CVRD, ou seja, são trabalhadores regidos pela CLT. A diferença no regime jurídico afeta o acesso desses empregados a alguns direitos concedidos aos servidores públicos, como plano de capacitação, função gratificada, entre outras. Nesse sentido, A13 relatou que, embora os anistiados tenham se desarticulado depois da reintegração, há ainda muitas questões a serem reivindicadas, pois a situação que vivenciam ainda é precária.

Pra quem é concursado da universidade, eles têm toda a chance. Mas nós, anistiados, não temos. [...] Nós não somos concursados pela universidade. Mas nós somos concursados pela Vale. [...] E dentro da Vale eu tinha promoções que aqui eu não tenho pela universidade. Essa promoção que eu teria que ter, seria do DNPM.

$\mathrm{Na}$ própria fala dos entrevistados, observa-se a separação entre os grupos, que são intitulados "nós" e "eles". Assim, tanto os anistiados como os servidores se colocam como parte de um grupo específico (nós), com características diferentes do outro grupo (eles). Azevedo (2016) também destaca essa segregação entre os grupos. Esse sentimento de injustiça pode prejudicar o envolvimento dos anistiados com a Universidade, de acordo com Siqueira e Gomide Júnior (2004). Percebe-se que, para os servidores entrevistados, essas diferenças seriam naturais e não exclusivas da Unifei, como destacado por S1: “Alguns se sentem também um pouco $[\ldots]$ Marginalizados. [...] Mas novamente, isso é uma coisa que acontece em qualquer instituição, a gente tem que ter um trabalho de tentar amenizar isso o máximo possível."

Outros servidores entrevistados citaram que algumas atribuições tendem a fazer com que os empregados públicos se sintam mais "marginalizados" ou "menos integrados", como a realização do serviço de limpeza. Assim, do mesmo modo que atuar na área administrativa pode conceder mais status a alguns empregados 
públicos e torná-los mais integrados, algumas atividades podem despertar nesses trabalhadores um sentimento de discriminação. Tomando-se como exemplo o serviço de limpeza, ressalta-se que a maioria dos trabalhadores cedidos à Unifei é do sexo masculino e encontram-se na faixa etária entre 60 e 69 anos. Outra ponderação é que essa atividade geralmente é terceirizada, tendo sido atribuída aos empregados públicos apenas temporariamente, em virtude de problemas contratuais. $\mathrm{O}$ fato de não ser uma atividade dos servidores da Unifei e de não ter sido a eles delegada, também pode ter contribuído para esse sentimento de diferenciação entre os grupos. Esse resultado contrapõe aos achados de Prata (2013), no qual os anistiados do Cefet se identificam com o trabalho, sentindo-se satisfeitos, motivados, por serem aceitos e bem-tratados.

\section{Processos de Identificação}

A identificação em relação à CVRD foi exaltada, no sentido de que ser funcionário da mineradora tornava a pessoa valorizada perante os habitantes da cidade. Ao serem demitidas, as pessoas perderam esse prestígio. A tendência, portanto, é que essas pessoas buscassem outras organizações reconhecidas pela sociedade, a fim de se tornarem valorizadas, resgatando a autoestima. Nesse contexto, todos os anistiados relataram que as pessoas com as quais convivem têm uma opinião positiva sobre a Unifei (Campus de Itabira) e sobre o fato de nela trabalharem. Estarem associados à Unifei pôde trazer de volta a esses trabalhadores o prestígio perdido. Essa situação tende a potencializar a identificação com a Unifei (Campus de Itabira), de acordo com Ashforth e Mael (1989), como é revelado por A13: "Só de se trabalhar na Unifei, pra mim já é uma grande honra. Eu não esperava. Eu não tinha um sonho desses. Igual eu trabalhava. 'Você trabalha onde?' Na Vale. Eu diferencio a Vale pela Unifei."

$\mathrm{Da}$ mesma forma, $88 \%$ dos entrevistados manifestaram ter uma boa imagem da Unifei. Os pontos mais destacados foram o ambiente da organização e as boas condições de trabalho, bem como a importância da Universidade para o município de Itabira e a possibilidade de que seja um novo caminho, diferente da mineração.

Também prevaleceram os bons sentimentos em relação à Universidade, pois $94 \%$ dos anistiados relataram que se sentem felizes e satisfeitos. $O$ fato de estarem vinculados a uma organização cuja atividade é importante para a cidade em que residem, portanto, pode torná-los mais satisfeitos por nela atuarem, como disse A4: "A gente tem que gostar, porque é simplesmente... É um futuro para com os jovens da cidade." Desse modo, $50 \%$ dos entrevistados mencionaram que se sentem orgulhosos ou envaidecidos de fazer parte do quadro de funcionários da Universidade. A comparação entre a situação atual (funcionário da Unifei) e anterior (funcionário da Vale) também foi frequente nas entrevistas realizadas com os anistiados.

Apesar de a maioria dos anistiados terem enfatizado o envolvimento com a Universidade, o entrevistado S3 citou que muitos empregados públicos hoje atuam na Unifei apenas por motivos econômicos, como 
completar o tempo para aposentadoria, complementar a renda ou lutar por uma possível indenização. Essa situação foi confirmada pelos próprios anistiados, como enfatiza A11: “Tem funcionário anistiado aqui... Que só pensa em vir aqui só pra receber. Não pensa em trabalhar."

O interesse, na verdade, da maioria daqui é o quê. Eles precisam da reintegração pra uma possível... De tá recebendo uma indenização do governo. Pelo tempo da demissão deles. Mas isso, quem curte isso na memória deles são esses advogados. [...] Porque na lei da anistia foi muito claro: não existe pagamento retroativo. (S3)

A maioria dos entrevistados (75\%) trocou de atividade funcional desde seu ingresso na Unifei. Eles passaram por diversos setores, em resposta à adequação à sua condição física, às suas habilidades e às necessidades da Universidade. Talvez em virtude dessas alterações, $75 \%$ dos empregados públicos entrevistados relataram que, no momento da pesquisa, não encontravam dificuldades para exercer as atribuições que lhe foram confiadas. Da mesma forma, $88 \%$ dos entrevistados se sentem reconhecidos pelo seu trabalho na Universidade, tendo mencionado, entre outros, que se sentem "úteis" e que são "elogiados". "Então eu sou reconhecido pela minha chefia, eles reconhecem meu trabalho, me tratam até muito bem, sou elogiado... [...] Não só pela minha chefia, como também... Eu já vi professores e mesmo o quadro técnico me elogiarem. [...] Isso pra mim é muita coisa" (A16).
Fica evidente a importância que eles atribuem ao reconhecimento e aos "elogios" recebidos de pessoas que eles consideram superiores a eles, tais como chefias, professores e alunos. Tal reconhecimento e valorização dos indivíduos se tornam elementos constitutivos dos vínculos organizacionais, condicionando seu comportamento na Unifei (Kramer \& Faria, 2007).

Entre as dificuldades encontradas pelos entrevistados estão: operar computadores, espaço físico, sobrecarga de trabalho, carência de pessoal para determinada função, falta de conhecimento sobre a atividade, falta de informação e material necessário para o trabalho. Apesar de todas as dificuldades, 94\% dos entrevistados relataram que se sentem "bem" e "satisfeitos" por trabalharem na Universidade, porém, quando questionados sobre o que os deixam felizes em trabalhar na Unifei, apenas $19 \%$ dos entrevistados mencionaram a atividade que desempenham como fonte de satisfação. Paralelamente a isso, $31 \%$ citaram o fato de terem um emprego e receberem um salário. Tal situação está relacionada à melhora das suas condições de vida, muitos funcionários reintegrados mantêm um sentimento de gratidão pela Unifei, o que interfere na percepção deles sobre a Universidade. Outras razões apresentadas para a satisfação são o ambiente de trabalho e tratamento recebido, a possibilidade de trabalhar e morar em Itabira e a imagem positiva da Unifei.

Também foi solicitado aos anistiados que indicassem a forma como se sentem em relação à Unifei (Campus de Itabira), a partir do 
modelo expandido de identificação definido por Kreiner e Ashforth (2004) e reproduzido na representação gráfica. Esse modelo apresenta quatro formas de relacionamento entre a pessoa e a organização: identificação neutra, superidentificação, desidentificação e identificação ambivalente.

Entre as repostas dos anistiados, tem-se que $81 \%$ indicaram a superidentificação, como o que representa melhor seu relacionamento com a Unifei (Campus de Itabira) e seus sentimentos em relação à organização. Tal posicionamento indicou um vínculo forte entre as partes, de modo que as principais características desses sujeitos teriam sido incorporadas da Unifei (Campus de Itabira), além da identidade deles como membros da organização ser mais representativa do que outras identidades que têm (Dutton et al., 1994). "O meu jeito de ser, a minha maneira de me comportar, de conduzir o meu dia a dia, eu acho que é bem parecido com os pensamentos da direção da Unifei e da entidade de maneira geral. Tá bem próximo... A gente interagindo bem" (A2).

Entretanto, assim como em relação a outros aspectos, a escolha do tipo de identificação pelos entrevistados não pode ser analisada de forma isolada. Nesse sentido, apesar da prevalência da superidentificação, muitos não souberam justificar a indicação ou explicaram a escolha em virtude do sentimento de gratidão pela Universidade. Algumas possíveis causas para essa contradição seriam a interpretação equivocada da figura ou a opção do entrevistado por indicar a "superidentificação", por acreditar que essa é a postura esperada pela Universidade (valorizando, portanto, sua atuação como funcionário).

Observou-se uma dificuldade dos entrevistados em geral (servidores e empregados públicos) em definir essas características organizacionais, o que sugere que o próprio Campus de Itabira da Unifei pode não ter uma identidade organizacional bem-definida. Alguns possíveis motivos para essa situação são o próprio tempo de existência do Campus, sua distância do campus-sede e até mesmo seu diferenciado processo de formação. O Campus de Itabira foi criado em 2008, distante aproximadamente 600 quilômetros da sede, Itajubá, a partir de um convênio de cooperação técnica e financeira estabelecido entre Unifei, Vale (antiga CVRD) e Prefeitura Municipal de Itabira. Assim, trata-se de um campus jovem, que não absorveu a cultura de seu centenário campus-sede, com um processo diferenciado de formação e muitas expectativas sobre os seus resultados.

A partir de tais constatações, cabe verificar se os processos de identificação verificados estão relacionados com $\mathrm{O}$ desempenho desses funcionários nas atividades que desempenham na Unifei, bem como na contribuição desses funcionários para a Universidade. Considerando a literatura sobre o assunto, supõe-se que os funcionários superidentificados com a Universidade tenham um bom desempenho, visto que estão alinhados com os objetivos da organização e compartilham de seu sucesso (ou fracasso).

\section{Implicações no Desempenho no Trabalho}


Vários vínculos organizacionais foram observados nesse grupo: identificação, envolvimento, sentimento de pertença e satisfação no trabalho. Também foi observado que o nível de satisfação dos anistiados, muitas vezes, não era relacionado às características da organização em si, mas a um sentimento de gratidão relativo à melhora das suas condições de vida desde que iniciaram suas atividades na Universidade.

Diante do exposto, cabe-nos questionar se os vínculos observados entre o grupo de funcionários anistiados e a Unifei (Campus de Itabira) têm refletido em ganhos efetivos para a Universidade, em termos de desempenho no trabalho. Como resultado, obteve-se a dedicação e o esforço como as características mais citadas. As características "dar o seu melhor" e ter "responsabilidade com o trabalho" parecem ser mais importantes para os entrevistados do que a própria qualificação para o cargo, pois, nas palavras de um deles, as competências para a função podem ser desenvolvidas, mas não a disposição para trabalhar e o comprometimento.

Assim, o gosto pelo trabalho ou por “dar o seu melhor", por exemplo, foi mencionado por $69 \%$ dos entrevistados como traços de sua personalidade. Observa-se que esses entrevistados procuraram aproximar a identidade pessoal do que é esperado pela Universidade, estabelecendo uma identificação entre as partes.

Eu acho que eu sou assim, igual a maioria fala, transparente. Que eu convivo bem com todo mundo. Não sou uma pessoa que fica assim retraída num lugar, sem falar com ninguém... [...] (Essas características) Me ajudam.
Principalmente com os alunos. Com os alunos porque aí eles têm confiança em mim. (A7)

O ambiente da universidade, as condições de trabalho e mesmo as características da função podem realmente afetar o desempenho de um funcionário (Coelho Júnior \& Borges-Andrade, 2011; Bendassolli \& Malvezzi, 2013). Os servidores entrevistados relataram que a função exercida pelo empregado público, o setor em que está lotado e a postura da chefia afetam o desempenho desses trabalhadores, o envolvimento e a contribuição destes para a Universidade.

Alguns dão até mais que as suas condições físicas lhe permitiriam. [...] Outros, assim, talvez até porque a atribuição que lhes coube não é uma atribuição que exija tanto. [...] Então, naquilo que lhe cabe, ele efetivamente faz. Mas não é uma pessoa que se destaque [...]. E tem aqueles que são, entre aspas, os problemáticos. (S2)

Alocar os trabalhadores em funções nas quais não se identificam ou que não permitem utilizar todo o potencial pode resultar em descontentamento e falta de motivação, refletindo na atuação desses funcionários, conforme relatado por S2 e S5. Nesse sentido, S2 ressalta que o empregado público pode não contribuir da forma como poderia por não receber atribuições compatíveis com as suas capacidades. Como são subutilizados e não "se destacam", acabam sendo pouco requisitados, gerando um acúmulo de atribuições para outros funcionários.

$\mathrm{O}$ fato de as expectativas acerca do desempenho esperado desses trabalhadores 
serem baixas torna mais difícil analisar a efetividade dos critérios da distribuição de funções. Ressalta-se que as atividades que envolvem esforço físico são socialmente menos valorizadas, de modo que nem todos os anistiados estão dispostos a exercê-las. Assim, os trabalhadores dispostos e com boas condições físicas são cada vez mais exigidos, gerando descontentamento e sentimento de injustiça como relatado por A8.

A gente tem muito mais consideração com a empresa, com a instituição, que muito funcionário. [...] Agora mesmo nós estamos [...] cavacando terra pra passar tubo. Isso... Eu não faço isso, por exemplo, nem lá em casa [...]. Aqui a gente tem que fazer. Certo? E outras pessoas sentadas o dia inteiro. (A8)

Também foi solicitado aos anistiados entrevistados que avaliassem o seu próprio desempenho no trabalho. Observou-se, nesse caso, uma condescendência, pois, embora 94\% acreditassem ter um bom desempenho, foram recorrentes expressões como: "a gente faz aquilo que está nas condições da gente" (A4) e "não tem como também, pela nossa idade" (A10). Esses trabalhadores, portanto, definiram padrões de desempenho condizentes com as suas limitações, de modo que pudessem avaliar o próprio desempenho como adequado.

Essa contradição pode estar relacionada às expectativas reduzidas sobre a atuação desses trabalhadores. Entretanto, outros fatores devem ser considerados, como o próprio conceito de desempenho e os critérios que cada entrevistado utilizou para se autoavaliar. Ao contrário dos servidores da Universidade, os anistiados não passam por nenhuma avaliação de desempenho, pois essa não é uma exigência legal (já que não estão sujeitos a um período de estágio probatório e não têm plano de carreira) e a Unifei optou por não fazê-lo. Portanto, solicitou-se à chefia imediata dos anistiados que preenchesse um formulário de avaliação sobre o desempenho de cada um deles, sendo que os itens a serem avaliados e a pontuação são os mesmos já adotados para avaliar os STAEs da Universidade.

A partir da análise dos formulários, não foi possível estabelecer uma correspondência entre a pontuação média atribuída aos entrevistados, durante a avaliação de desempenho, e o tipo de identificação indicado na representação gráfica. Visualizou-se, entretanto, que o anistiado com a menor pontuação média na avaliação de desempenho não apresentou nenhum dos componentes de identificação, embora o quadrante indicado na representação gráfica corresponda à superidentificação. Essa situação corrobora o pressuposto anteriormente levantado de que alguns entrevistados optaram por indicar a figura que julgavam valorizar a sua postura como funcionário.

Analisando individualmente as notas atribuídas a cada critério de avaliação, não foi visualizada relação entre a identificação dos entrevistados e a pontuação atribuída aos critérios assiduidade, pontualidade, qualidade e produtividade, administração das condições de trabalho, habilidade técnica e atualização e informações. Ou seja, para esses critérios, os entrevistados que demonstraram maior identificação com a Universidade não foram necessariamente os mais bem-pontuados, e vice- 
versa. Já nos quesitos trabalho em equipe e relacionamento interpessoal, os entrevistados que não apresentaram nenhum dos componentes de identificação listados obtiveram as menores pontuações verificadas, o que indica que a falta de identificação organizacional pode estar impactando no desempenho.

Ainda foi possível verificar que dois entrevistados obtiveram nota máxima em todos os fatores de avaliação, o que significa que o desempenho deles estaria acima das expectativas em todos os critérios. Desses entrevistados, um deles apresentou vários componentes de identificação com a Unifei, tendo escolhido a superidentificação. O outro entrevistado mais bem-avaliado optou pela identificação neutra e não apresentou tantos traços de identificação organizacional em seus depoimentos, mas relatou que a dedicação, bem como o gosto pelo trabalho e por ajudar as pessoas, faz parte de seus traços pessoais. Tal situação caracteriza que o bom desempenho desse entrevistado deve-se muito mais a suas características pessoais e à identificação com o trabalho, como apontado por Tavares et al. (2016).

Entretanto, tais resultados não determinam a dissociação entre identificação organizacional e desempenho. A partir dos relatos dos entrevistados, verificaram-se várias questões que impactam no desempenho dos empregados públicos, como idade, problemas de saúde, desatualização ou desconhecimento da atividade. Contudo, as avaliações de desempenho não refletiram esses pontos. No quesito "habilidade técnica e atualização", apenas três entrevistados foram classificados pela chefia como "atendem parcialmente às expectativas", enquanto dez "atendem às expectativas" e três estão "acima das expectativas”. Essa situação confirma o ponto já levantado inicialmente de que, em geral, há uma adaptação das expectativas em relação às potencialidades dos anistiados.

Percebeu-se, portanto, que, considerando a pontuação atribuída pela chefia imediata aos entrevistados, a pesquisa realizada não apresentou relações entre o grau de identificação com a Unifei (Campus de Itabira) e o desempenho no trabalho dos anistiados. Entretanto, a análise das entrevistas e a revisão da literatura realizadas não nos permitem excluir a importância da identificação para os resultados organizacionais e o desempenho individual no trabalho.

\section{Considerações Finais}

Este trabalho foi realizado com o objetivo de compreender o processo de identificação dos empregados públicos cedidos à Unifei (Campus de Itabira) em relação à Universidade, bem como as implicações desse processo para o desempenho dos funcionários. Para tal, buscou-se conhecer o processo de anistia da CVRD, compreendendo os significados que este representou para as pessoas envolvidas; identificar a intensidade da identificação dos entrevistados com a Unifei, sob a perspectiva destes; e analisar as implicações para o desempenho no trabalho da identificação com a Universidade.

No que tange ao processo de anistia e seus significados, observou-se que parte dos entrevistados tinha forte identificação com a 
CVRD na época das demissões. Por esse motivo, a dispensa não apenas foi recebida pelos entrevistados com surpresa e um sentimento de injustiça, mas também ocasionou perda de status social (considerando que o vínculo com a mineradora era muito valorizado em Itabira) e da própria identidade construída pelo trabalhador.

Os significados e os impactos dessas demissões variaram bastante, de acordo com as características pessoais dos envolvidos, a capacidade de eles se reerguerem profissional e financeiramente e a intensidade da identificação com a antiga empresa. Dessa forma, os trabalhadores demitidos da CVRD durante o governo Collor tiveram diferentes trajetórias profissionais, até que foi alcançado o direito de reintegração. Prevaleceram, porém, as situações em que houve um prejuízo na qualidade de vida, em virtude da redução dos rendimentos, da necessidade de se mudar de cidade para trabalhar, da perda da identidade social e da autoestima.

A maior parte dos anistiados entrevistados relatou que se sentiram bemrecebidos e acolhidos na Unifei (Campus de Itabira), embora tenha se observado um despreparo da Universidade ao recebê-los. Em muitos casos, quando os anistiados se apresentavam ao trabalho, não havia uma função definida para executarem ou os procedimentos necessários para que a executassem não tinham sido tomados, de modo que ficavam à disposição por algum tempo. Alguns anistiados relataram que sentiram um "receio" ou "rejeição" por parte dos servidores da Universidade, como se não pudessem mais contribuir em função da idade que tinham ou estivessem ocupando vagas de servidores que poderiam contribuir mais.

Foi percebida uma separação entre grupos na Universidade (STAEs e anistiados), com níveis variados de separação ou de integração conforme as características de cada pessoa e da função desempenhada - o anistiado pode se tornar mais próximo dos STAEs ou dos docentes do que dos seus pares, por exemplo, em virtude das suas atribuições ou de suas próprias características pessoais. $\mathrm{O}$ tipo de atividade também pode causar separação dentro do próprio grupo, sendo algumas atividades fonte de status (como a administrativa) e outras fonte de estigma (como o serviço de limpeza).

A despeito de tais situações, foram observados vários componentes de identificação no grupo dos anistiados. Quando solicitados que indicassem o que melhor representava os sentimentos em relação à Unifei, consideraramse superidentificados. Entretanto, não se pode determinar o grau de identificação dos anistiados apenas com base nas indicações da representação gráfica, visto que algumas foram contraditórias aos depoimentos da entrevista.

Esta pesquisa ainda procurou comparar o desempenho individual dos anistiados com a identificação destes em relação à Unifei, a partir da avaliação realizada pela chefia imediata. No geral, não foi observada uma relação direta entre esses dois aspectos. Entretanto, deve-se considerar o componente subjetivo do processo de avaliação de desempenho, já que as características pessoais do avaliador, o contexto em que está inserido, a forma como interpreta o instrumento de avaliação e até o relacionamento 
com o avaliado podem interferir nos resultados da avaliação e, consequentemente, inviabilizar a utilização destes para a pesquisa. Considerando essas questões, a análise das entrevistas e a revisão da literatura realizada, entende-se que não é possível excluir a importância que a identificação pode representar para o desempenho no trabalho e os resultados da organização.

Em suma, avaliam-se como positivos os resultados da incorporação dos anistiados no quadro de funcionários da Unifei (Campus de Itabira), apesar das várias dificuldades relatadas. Observa-se, também, que vários componentes de identificação foram verificados nos anistiados entrevistados, o que pode estar contribuindo para o resultado positivo.

Embora a impossibilidade de generalizar as conclusões deste estudo seja uma limitação própria do método adotado, acreditase que ele é de interesse de várias organizações públicas, especialmente aquelas que receberam funcionários anistiados e que vivem situações semelhantes. Este estudo contribui, também, para aprofundar o debate teórico sobre a identificação organizacional e avaliação de desempenho no processo de compreensão da relação psicológica estabelecida entre $\mathrm{O}$ indivíduo anistiado e a organização que o recebeu. Outras limitações do estudo foram o próprio instrumento de avaliação de desempenho, que não foi elaborado especificamente para os anistiados, e o estudo realizado de maneira transversal. Pesquisas futuras poderiam realizar um estudo longitudinal e acompanhar o desempenho dos empregados públicos, a fim de gerar resultados mais conclusivos, além de estudar outros vínculos organizacionais. Seria interessante também realizar um estudo similar com relação aos servidores, a fim de comparar os resultados.

\section{Referências}

Andrade, R. (2013). Anistiados da Vale pedem ajuda política para retornarem a Itabira. De fato online, Itabira. Recuperado em 14 fevereiro, 2017, de http://www.defatoonline.com.br/noticia s/ultimas/30-10-2013.

Ashforth, B., \& Mael, F. (1989). Social Identity Theory and the Organization. The Academy of Management Review, 14(1), 2039. Retrieved November 11, 2016, from http:/ /www.jstor.org/stable/258189. doi: 10.2307 / 258189.

Ashforth, B., Harrison, S. H., Corley, K. G. (2008). Identification in Organizations: an Examination of Four Fundamental Questions. Journal of Management, 34(3), 325-361, Retrieved June 8, 2016, from https://doi.org/10.1177/0149206308316 059.

Azevedo, R. C. M. S. (2016). O bistórico de lutas dos profissionais readmitidos na Universidade Federal Rural do Rio de Janeiro. Dissertação de mestrado, Universidade Federal Rural do Rio de Janeiro, UFRRJ, Rio de Janeiro, Brasil. Recuperado em 8 abril, 2018, de http://localhost:8080/tede/handle/jspui /1508.

Bardin, L. (1977). Análise de conteúdo. Lisboa: Edições 70.

Bastos, A. V. B., Rodrigues, A. C. de A., Moscon, D. C. B., Silva, E. E. da C. e, \& Pinho, A. P. M. (2013).

Comprometimento no trabalho: fundamentos para a gestão de pessoas. In O trabalho e as organizações: atuações a partir da Psicologia. Porto Alegre: Artmed.

Bendassolli, P. (2012). Desempenho no trabalho: revisão da literatura. Psicologia Argumento, 30(68). 
Bendassolli, P. F., \& Malvezzi, S. (2013). Desempenho no trabalho: definições, modelos teóricos e desafios à gestão. In $O$ trabalho e as organizações: atuações a partir da Psicologia. Porto Alegre: Artmed.

Brasil, República Federativa do Brasil. (2015). Biblioteca da Presidência da República. Ex-presidentes: Fernando Collor. Brasília, Presidência da República. Recuperado em 24 outubro, 2016, de http://www.biblioteca.presidencia.gov.br /ex-presidentes/fernando-collor/ biografia-periodo-presidencial.

Brasil, República Federativa do Brasil. (2012). Câmara dos Deputados. Demitidos no Governo Collor querem tratamento igual ao de outros servidores. Brasília, Câmara dos Deputados, Agência Câmara Notícias. Recuperado em 2 setembro, 2016, de http://www2.camara.leg.br/camaranotici as/noticias/administracaopublica/430656-demitidos-no-governocollor-querem-tratamento-igual-ao-deoutros-servidores.html.

Coelho Junior, F. A., \& Borges-Andrade, J. E. (2011). Efeitos de variáveis individuais e contextuais sobre desempenho individual no trabalho. Estudos de Psicologia (Natal), 16(2), 111-120. Recuperado em 23 março, 2016, de https://dx.doi.org/10.1590/S1413294X2011000200001.

Creswell, J. W. (2010). Projeto de pesquisa: métodos qualitativo, quantitativo e misto (3a ed.). Porto Alegre: Artmed.

Decreto n. 93, de 23 de junho de 1993. (1993). Cria Comissão Especial para examinar dispensas de servidores públicos e de empregados de cargos e empregos efetivos de órgãos e entidades da Administração Pública Federal. Recuperado em 25 março, 2016, de http://www.planalto.gov.br/ccivil_03/dn n/Anterior\%20a\%202000/Dnn1-23-0693.htmhttp://.

Dubar, C. (2005). A socialização: a construção das identidades sociais e profissionais. São Paulo: Martins Fontes.
Dutton, J., Dukerich, J., \& Harquail, C. (1994). Organizational Images and Member Identification. Administrative Science Quarterly, 39(2), 239-263. Retrieved November 8, 2016, from http://hdl.handle.net/2152/29308. doi: 10.2307 / 2393235.

Fernandes, M. E. R., Marques, A. L., \& Carrieri, A. de P. (2009). Identidade organizacional e os componentes do processo de identificação: uma proposta de integração. Cadernos EBAPE.BR, 7(4), 687-703. Recuperado em 8 setembro, 2016, de https:/ / dx.doi.org/10.1590/S167939512009000400011.

Fogaça, N., \& Coelho Junior, F. A. (2015). A hipótese "trabalhador feliz, produtivo": o que pensam os servidores públicos federais. Cadernos EBAPE.BR, 13(4), 759775. Recuperado em 8 setembro, 2016, de https://dx.doi.org/10.1590/1679395126953.

Kramer, G. G., \& Faria, J. H. de. (2007). Vínculos organizacionais. Revista de Administração Pública, 41(1), 83-104. Recuperado em 2 junho, 2016, de http:/ / bibliotecadigital.fgv.br/ojs/index. $\mathrm{php} / \mathrm{rap} /$ article/view/6881/5454.

Kreiner, G. E. \& Ashforth, B. E. (2004), Evidence toward an Expanded Model of Organizational Identification. J. Organiz: Behav., 25, 1-27. Retrieved June 2, 2016, from https://doi.org/10.1002/job.234.

Lei n. 8.878, de 11 de maio de 1994. (1994). Dispõe sobre a concessão de anistia nas condições que menciona. Recuperado em 25 março, 2016, de http://www2.camara.leg.br/legin/fed/lei /1994/lei-8878-11-maio-1994-372572normapl.html.

Motowidlo, S. J., Borman, W. C., \& Schmit, M. J. (1997). A Theory of Individual Differences in Task and Contextual Performance. Human Performance, 10(2), 71-83. Retrieved June 2, 2016, from https://doi.org/10.1207/s15327043hup1 002_1. 
Mourão, L., Monteiro, A. C. F., \& Viana, V. R. (2014). A influência do desenvolvimento profissional e da identificação organizacional na satisfação no trabalho. Psico, 45(2)198-208. Recuperado em 12 julho, 2016, de http:/ /dx.doi.org/10.15448/19808623.2014.2.13470.

Peixoto, A. L. A., \& Caetano, A. (2013). Avaliação de desempenho. In L. O. Borges \& L. Mourão. O trabalho e as organizações: atuações a partir da Psicologia (pp. 528-556). Porto Alegre: Artmed. Recuperado em 12 julho, 2016, de http:/ /dx.doi.org/10.1590/141373722407316.

Prata, M. M. F. (2013) Prazer ou sofrimento no trabalho?: a percepção dos empregados públicos reintegrados ao CEFET-MG. Dissertação de mestrado, Faculdade Novos Horizontes, Belo Horizonte, Brasil. Recuperado em 3 abril, 2018, de http://www.unihorizontes.br/mestrado2 /prazer-ou-sofrimento-no-trabalho-apercepcao-dos-empregados-publicosreintegrados-ao-cefet-mg/.

Pratt, M. G. (1998). To Be or not To Be: Central Questions in Organizational Identification. In D. A. Whetten \& P. C. Godfrey (Eds.). Foundations for Organizational Science. Identity in Organizations: Building Theory through Conversations (pp. 171-207). Sage Publications, Inc. Retrieved April, 3, 2018, from https://doi.org/10.4135/9781452231495. n6.

Rho, E., Yun, T., \& Lee, K. (2015). Does Organizational Image Matter?: Image, Identification, and Employee Behaviors in Public and Nonprofit Organizations. Public Admin Rev, 75, 421-431. Retrieved June 12, 2016, from https://doi.org/10.1111/puar.12338.

Siqueira, M. M. M., \& Gomide, S., Jr. (2004). Vínculos do indivíduo com o trabalho e com a organização. In J. C. Zanelli, J. E. Borges-Andrade \& A. B. Bastos (Orgs.). Psicologia, organizações e trabalho no Brasil (pp. 300-328). Porto Alegre: Artmed.
Tajfel, H. (1982). Social Psychology of Intergroup Relations. Annual Review of Psychology, 33, 1-39. Retrieved October 10, 2016, from http://dx.doi.org/10.1146/annurev.ps.33 .020182 .000245 .

Tavares, S. M., van knippenberg, D., \& van Dick, R. (2016). Organizational Identification and "Currencies of Exchange": Integrating Social Identity and Social Exchange Perspectives. Journal Of Applied Social Psychology, 46(1), 34-45. Doi: $10.1111 /$ jasp.12329.

Recebido em: 6/2/2018

Aprovado em: 23/4/2018 